(Utilization) 1, A (Govt. of India Press, New Delhi 1939), Mr. V. D. Limaye gives authentic information, on the possible uses and comparative strengths of thirty-six common Indian timbers and of six commonly imported timbers (three of which come from Burma) of different genera and species. This demonstrates the wealth of fine timbers there are in India. Yet three quarters of a century ago or less the bulk of the population in India, including the British, relied chiefly on three timbers only, according to situation-teak, sal (Shorea) and deodar.

\section{Meteorology of the Australasian Antarctic Expedition}

The Australasian Antarctic Expedition of 1911-14 under the leadership of Sir Douglas Mawson seems an episode of the remote past, for so many better equipped expeditions have intervened. The latest of the scientific reports of this expedition is the fifth of the series and is in three parts (Australasian Antarctic Expedition, 1911-14. Scientific Reports. Series B, Vol. 5: Meteorology. Part 1: Records of the Queen Mary Land Station; Part 2: Meteorological Log of the S.Y. "Aurora"; Part 3: Sledge Journey Weather Records; Appendix, Macquarie Island Weather Notes for 1909-1910-1911. Pp. $\mathrm{x}+\mathbf{2 8 2}+4$ plates. Sydney: Government Printer, 1940. 40s.). It is concerned with meteorology. Part 1 of this volume deals with the records of the Queen Mary Land station - the 'Grottoes'-in latitude $66^{\circ} \mathrm{S}$., longitude $95^{\circ}$ E. ; Part 2 covers the meteorological log of the S.Y. Aurora, and Part 3 the weather records of the sledge journeys ; an appendix includes the daily weather records made at Macquarie Island by Otto Bauer's sealing party from August 1909 to July 25, 1910, and January 1 to December 12, 1911.

Although the report is largely statistical, there are some excellently reproduced photographs, at the end of the volume, of scenes of meteorological interest. Four of these show characteristic features of the edge of the Antarctic Continent that must, judging from the descriptions of others who have written about the same subject, be very typical. Thus, in Plate 4, Fig. 2, a canopy of strato-cumulus cloud is seen over Commonwealth Bay, with cloudless sky over the continent to the south. It is a scene of peace and beauty, the ripples in the sea showing that there was only a light westerly wind blowing. In Plate 3, Fig. 1, the sky is still fartly cloud-free; but the clouds look like alto-cumulus and the horizon is a dark smudge indicating the approach of a blizzard. In Plate 4, Fig. 1, a sledging party on the plateau interior of Adelie Land appears to be preparing to weather a blizzard that is presaged by dense masses of cirrus cloud. The sequence is completed by Plate 2, Fig. 2, in which cumulo-nimbus clouds are breaking up just after a blizzard north of the Mertz Glacier Tongue. The bulk of the volume consists of undiscussed meteorological tables, but a footnote to p. 16 says that "Dr. E. Kidson has been engaged preparing two volumes analysing and discussing the Expedition's meteorological data. This will be published in due course".

\section{Epidemiology in the Army}

IN a recent article (Ann. Int. Med., 13, 2229 ; 1940) Lieut.-Colonel J. S. Simmons, of the Medical Corps of the United States Army, divides the hazards of military life into three groups according as they arise in peace-time service, during mobilization or in actual warfare. In peace-time the soldier's life is as safe as, if not safer than, the civilian's, as he has been carefully selected, housed in modern barracks, fed on a balanced diet of wholesome food and forced to take adequate exercise. $\mathrm{He}$ is trained in physical hygiene, and his health is under medical supervision. During mobilization, though efforts are made to continue existing medical facilities, the rapid accumulation of susceptible recruits from all parts of the country frequently results in epidemics. In actual warfare, the soldier is not only faced with the risk of injury and death from battle, but is also exposed to infection. Between April 1917 and December 1919 when the United States Army was engaged in that War the casualties from all quarters were 50,000 deaths due to battle and 58,000 deaths caused by disease. The principal diseases to which the soldier is exposed during mobilization and war are wound infections, the morbidity and mortality of which have undergone a striking decrease since the introduction of antiseptic surgery, gastro-intestinal infections due to contaminated food and drink, including enteric fever, dysentery and cholera, venereal infections, the admission rate for which in the United States Army was 87 per 1,000, respiratory infections, including influenza, pneumonia, scarlet fever, diphtheria, measles, mumps and cerebrospinal fever, and insect-borne infections, such as malaria, yellow fever, typhus and plague.

\section{History of Blood Transfusion}

IN a recent thesis (Thèse de Paris 1940, No. 344) on this subject, Dr. Edmond Ecale states that the history of the transfusion of blood is intimately connected with the discovery of the circulation. Although even in the prehistoric period the idea of the operation had been conceived, it was in the country of Harvey that the first scientific attempts of transfusion were made, namely, by Christopher Wren in 1656 and Edmund King in 1667. Jean Denis was the first to carry out transfusion from an animal to man in 1667 , and was followed a few months later by Richard Iower in England, Riva in Italy and Kaufmann in Germany. Transfusion of blood was prohibited by the Châtelet edict in 1668, and almost fell into oblivion for nearly a century and a half. The first successful transfusion of blood from man to man, which was carried out by the obstetrician James Blundell in 1825, marked an important progress in the history of the method, and was performed with a syringe containing defibrinated blood to prevent coagulation. The introduction, however, in 1879 of intravenous injection of normal saline which was a simpler and safer method interfered with the progress of transfusion of blood for some time. After the beginning of the twentieth century, transfusion of blood was again revived on the discovery of agglutinins, 